\title{
Juventude, Trabalho e Projetos de Vida: Ninguém Pode Ficar Parado
}

\author{
Nobody Can Be Motionless: \\ Youth, Work and Projects of Life
}

Juventud, Trabajo y Proyectos de Vida: Nadie Puede Quedarse Parado

Ana Augusta Ravasco Moreira Maia \& Deise Mancebo

Universidade do Estado do Rio de Janeiro

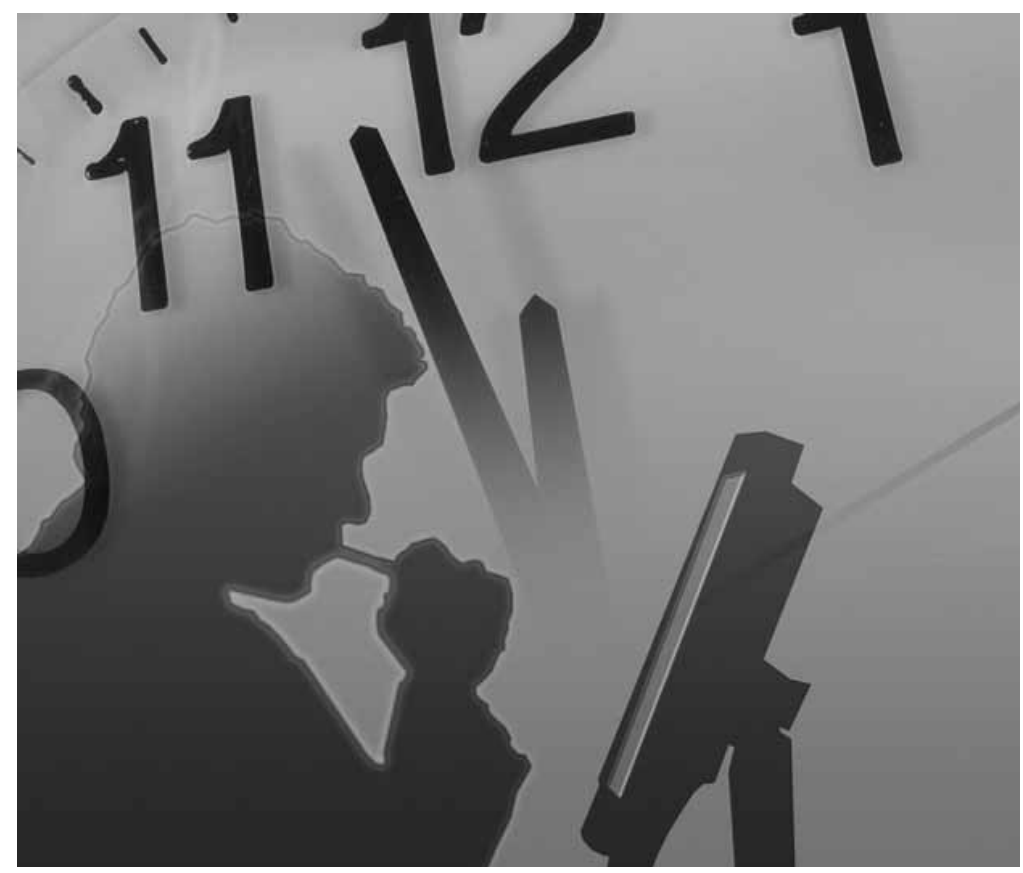


Resumo: $\mathrm{O}$ texto tem por objetivo analisar e discutir as maneiras pelas quais os jovens, na atualidade, vêm construindo trajetórias, narrativas e projetos de vida a partir das novas configurações assumidas pelo trabalho, e apresenta, inicialmente, as concepções teóricas centrais que nortearam a pesquisa: o contemporâneo, as mudanças ocorridas no mundo do trabalho, a juventude e seus projetos de vida. Expõe, a seguir, o estudo empírico realizado, através de entrevistas semidirigidas, com jovens de classe média alta do Rio de Janeiro, universitários e estagiários de uma grande empresa local, cujos depoimentos foram analisados pela análise de conteúdo e pela análise do discurso. Ao final, o texto apresenta e analisa as principais temáticas localizadas nos depoimentos: (1) as percepções, vivências e experiências relatadas, pelos entrevistados, sobre os estágios, que remeteram, de maneira direta ou indireta, a um aprendizado de construção pessoal e/ou de adequação a um determinado perfil valorizado e reconhecido no atual mercado de trabalho; (2) os contatos, que emergem como facilitadores para a inserção e a permanência no mercado de trabalho e (3) a abordagem da entrada na vida adulta e a concepção de futuro apresentado pelos jovens como um mosaico de possibilidades, que assentou-se, de fato, em uma concepção de presente alongado.

Palavras-chave: Jovens. Trabalho. Projeto de vida. Vida adulta.

Abstract: The text aims to analyze and to discuss the ways in which youngsters, nowadays, have been constructing ways, narratives and life projects from the new configurations assumed by work. It presents, initially, the central theoretical conceptions that guided the research: the contemporary life, the changes in the work environment, the youth and its life projects. It then displays the empirical study conducted through semi-directed interviews, with high middle class youngsters from Rio de Janeiro, university students and trainees in a big company from the same city, whose testimonials were analyzed by the content analysis and discourse analysis. Finally, the text presents and analyzes the main themes found in the testimonials: (1) the perceptions and experiences related by the interviewed subjects on the period they were trainees, which referred, in a direct or indirect way, to an apprenticeship of personal construction and/or adequacy to a particular "profile" valued and recognized in the current labour market, (2) the "contacts", that emerge as facilitators for the insertion and permanence in the labour market and (3) the approach of entrance into adult life and the conception of future presented by the youngsters as a mosaic of possibilities, that was based, in fact, in a conception of "prolonged present".

Keywords: Young adults. Work. Life project. Adult life.

Resumen: El texto tiene por objetivo analizar y discutir las maneras por las cuales los jóvenes, en la actualidad, viene construyendo trayectorias, narrativas y proyectos de vida a partir de las nuevas configuraciones asumidas por el trabajo, y presenta, inicialmente, las concepciones teóricas centrales que nortearon la pesquisa: lo contemporáneo, las mudanzas ocurridas en el mundo del trabajo, la juventud y sus proyectos de vida. Expone, a seguir, el estudio empírico realizado, a través de entrevistas semi-dirigidas, con jóvenes de clase media alta de Rio de Janeiro, universitarios y becarios de una gran empresa local, cuyas declaraciones fueron analizadas por el análisis de contenido y por el análisis del discurso. Al final, el texto presenta y analiza las principales temáticas localizadas en las declaraciones: (1) las percepciones, vivencias y experiencias relatadas, por los entrevistados, sobre los períodos de prácticas, que remitieron, de manera directa o indirecta, a un aprendizaje de construcción personal y/o de adecuación a un determinado perfil valorizado y reconocido en el actual mercado de trabajo; (2) los contactos, que emergen como facilitadores para la inserción y la permanencia en el mercado de trabajo y (3) el abordaje de la entrada en la vida adulta y la concepción de futuro presentado por los jóvenes como un mosaico de posibilidades, que se asentó, de hecho, en una concepción de presente alargado.

Palabras clave: Jovenes. Trabajo. Proyecto de vida. Vida adulta.

Este texto tem como objetivo analisar e discutir as maneiras pelas quais os jovens, na atualidade, vêm construindo trajetórias, narrativas e projetos de vida a partir das novas configurações assumidas pelo trabalho. Nessa perspectiva, tanto sujeito quanto subjetividade são entendidos como produções históricas na relação dialética com a realidade objetiva. Para nós, e como afirma Gonçalves (2002), a subjetividade é constituída através de mediações sociais, não pode ser tomada como universal ou imutável, não sendo possível compreender as formações da subjetividade de maneira descolada das formações sociais nas quais estas se constituem, pois cada momento histórico e cada sociedade colocam em funcionamento algum modo de subjetivação (Mancebo, 2004).

As aceleradas transformações que vêm ocorrendo na sociedade ocidental desde o fim do século XX têm provocado diversos impactos 
...como apontam Castro e Corrêa

(2005), a juventude passa por uma situação paradoxal: ao mesmo tempo em que tem diante de si uma amplitude maior de possibilidades, muitas vezes não tem o que escolher. em todas as esferas de vida dos sujeitos contemporâneos. Essas mudanças fizeram com que o processo de passagem para a vida adulta e a própria noção de juventude, diante de um panorama repleto de paradoxos, no qual o risco e a incerteza permeiam o imaginário coletivo, adquirissem um caráter difuso e múltiplo, que coloca novos desafios para os jovens de uma maneira geral.

Em consonância com as análises que sustentam a centralidade do trabalho como categoria de estruturação da subjetividade (Antunes, 2000; Castel, 1998; Mészáros, 2006), entende-se o trabalho como instância privilegiada de inserção social, que comparece, de modo decisivo, para as produções de subjetividade, possuindo papel fundamental na construção de projetos de vida dos jovens que possibilitem o desenvolvimento de trajetórias e narrativas consistentes. Sob esse ponto de vista, as inúmeras transformações que vêm ocorrendo no mundo do trabalho-como o crescimento do desemprego, a diminuição do emprego estável e assalariado, a precarização e novas formas de trabalho flexível - afetam os habitantes não apenas dos países subdesenvolvidos mas também os dos países capitalistas avançados.

Os jovens, particularmente, são afetados diretamente por essa realidade, com contornos mais dramáticos para aqueles advindos das classes socioeconômicas mais pobres. A crise do trabalho no Brasil, conforme discute Pochmann (2004), vem sendo responsável pelo distanciamento cada vez maior entre o que os jovens gostariam de ser - as expectativas que têm com relação ao futuro - e o que eles realmente conseguem ser - a forma com que acabam tendo que lidar com a realidade que a eles se impõe no dia a dia.

Além disso, a lógica do mercado de trabalho, na qual vigora, dentre outros aspectos, a ideia de que a responsabilidade pelos próprios sucessos ou fracassos é apenas dos próprios indivíduos, unida ao fato de as instâncias políticas e sociais serem cada vez menos protetoras, fazem com que a juventude, muitas vezes, careça de orientações que facilitem suas escolhas e possíveis caminhos a serem seguidos. Dessa forma, como apontam Castro e Corrêa (2005), a juventude passa por uma situação paradoxal: ao mesmo tempo em que tem diante de si uma amplitude maior de possibilidades, muitas vezes não tem o que escolher. Diante da aceleração desenfreada do ritmo da vida, da fugacidade dos (des) encontros, do peso de ter que alcançar o sucesso arcando com toda a responsabilidade pelo resultado de suas empreitadas, o sujeito contemporâneo e especialmente os jovens encontram-se, muitas vezes, acuados no cotidiano.

Para Dubar (2005), alguns desses fenômenos observados na sociedade contemporânea, como as dificuldades de inserção profissional da juventude, o aumento das exclusões sociais, o mal-estar vivenciado diante das transformações e a confusão das categorias que servem para a definição de si mesmo, entre outros, fazem com que atualmente seja comum falar em crise das identidades. Sem pretender problematizar e discutir as noções de identidade e de socialização tal como abordadas pelo autor, é indiscutível que a dimensão profissional como processo de socialização no que concerne à construção e reconstrução das identidades e, assim, das próprias trajetórias de vida, ganha relevo dentro de um cenário em que o emprego vem se tornando cada vez mais raro e o mundo do trabalho, sofrendo mutações profundas.

Pelo exposto, a temática da juventude, no Brasil e no mundo, vem ganhando extrema importância, visto que os jovens passam, no cenário atual, por uma fase de transição extremamente complexa e, não raramente, dolorosa. Assim, a partir dessas considerações iniciais, seguem algumas análises mais consistentes acerca dos principais eixos temáticos nos quais o estudo se desdobra - o contemporâneo, as mudanças no mundo do trabalho, a juventude e os projetos de vida para apresentarmos, ao final, estudo empírico realizado, através de entrevistas semidirigidas, com jovens de classe média alta, do Rio de Janeiro, universitários e estagiários de uma grande empresa local. 
Para Lipovetsky (2004), a

sociedade em

que vivemos seria

liberal, fanática

pelo desempenho,

caracterizada

pelo movimento,

pela fluidez e pela

flexibilidade, e

estaria alicerçada

em três axiomas

principais: o

mercado, a

eficiência técnica

e o indivíduo.

\section{O contemporâneo em flashes}

O mundo ocidental vem passando, desde o fim do século $X X$, por intensas modificações que trouxeram transformações profundas nas diversas esferas do arranjo social. Essas transformações são analisadas por diversos teóricos contemporâneos, como Bauman (1999, 2001, 2004) e Lipovetsky (2004, 2007), e trazem à tona a emergência de novos modos de subjetivação.

Segundo Bauman (2001), nossa época seria uma versão individualizada e privatizada da modernidade, caracterizada pela desregulamentação: nela, decompõem-se as forças que poderiam ter mantido a questão da ordem e do sistema na agenda política e, por conseguinte, observa-se o esfacelamento dos elos que entrelaçam as escolhas individuais em projetos e ações coletivas.

Para Lipovetsky (2004), a sociedade em que vivemos seria liberal, fanática pelo desempenho, caracterizada pelo movimento, pela fluidez e pela flexibilidade, e estaria alicerçada em três axiomas principais: o mercado, a eficiência técnica e o indivíduo. O autor observa, ainda, que se trata de uma sociedade em que prevalece a valorização do desempenho, na qual todos são intimados a ser superativos e operacionais nos diversos âmbitos da vida, a elevar ao máximo os potenciais de forma, de saúde, de sexualidade e de beleza. O ideal de superar-se e vencer invade a existência como um todo, e torna necessário ser competitivo, assumir riscos, atingir o topo e correr atrás da suposta excelência e do sucesso (Lipovetsky, 2007).

Para o autor, algumas mudanças mais importantes são as que se referem ao ambiente social e à relação com o presente. Frente ao desenvolvimento desenfreado das tecnologias de informação, da lógica de globalização que se exerce independentemente dos indivíduos, da crescente precarização do emprego e da instituição do desemprego estrutural, o sujeito contemporâneo é corroído pela ansiedade e pelo medo com relação ao futuro incerto.
São transformadas também as relações com o tempo e com o espaço, coordenadas fundamentais de representação dos sistemas sociais, através das quais o ser humano não só aprendeu a se orientar no universo como também a desenvolver sua narrativa subjetiva (Elias, 1998). Na realidade, conforme Harvey (1994), a própria história do capitalismo tem se caracterizado pela constante aceleração do ritmo da vida e pelo concomitante aniquilamento das barreiras espaciais, que acabaram por fazer com que o mundo parecesse encolher em suas dimensões. $\mathrm{O}$ autor denomina essa dinâmica "compressão tempo-espaço" para indicar "processos que revolucionam as qualidades objetivas do espaço e do tempo, a ponto de nos forçarem a alterar, às vezes radicalmente, o modo como representamos o mundo para nós mesmos" (p. 219).

À medida que o espaço parece retrair-se e que os horizontes temporais se reduzem a um ponto - o presente - os seres humanos têm que aprender a lidar com o sentido de encolhimento dos seus mundos espacial e temporal, trazendo à tona, conforme sugere Bauman (1999), uma nova modalidade de ser e de estar no mundo: o nomadismo. Querendo ou não, impõe-se aos homens e às mulheres atuais o permanente movimento. O nomadismo não diz respeito apenas ao movimento físico do corpo, mas refere-se à impossibilidade de se ficar parado, pois os pontos de referência são voláteis e cambiantes, desaparecendo de nossa vista antes que consigamos entendê-los e tomá-los como base para nosso comportamento.

A lógica da volatilidade torna extremamente difícil planejamentos de longo prazo (Bauman, 2001), e o mundo atual parece ter se tornado mais frágil e errático, de maneira que investir em realizações de vida inteira, quando os valores se desvalorizam em curtíssimo período de tempo, pode parecer maneira inadequada de habitar um cenário repleto de produtos projetados para imediata obsolescência. A mentalidade de curto prazo substitui a de longo prazo, e, como as regras do jogo não param de mudar, a estratégia mais racional 
encontrada pelos homens da atualidade é a de viver um dia de cada vez.

A lógica do descartável, associada à ênfase no curto prazo, desconjuntam as noções de tempo linear, no qual passado, presente e futuro formavam um todo coerente que davam sustentação à construção de trajetórias individuais e coletivas mais consistentes.

\section{Mutações do trabalho}

Nos últimos trinta anos, o mundo do trabalho tem passado por significativas transformações que suscitaram, na atualidade, intenso debate acerca de sua centralidade como categoria constituinte de modos de agir, sentir e pensar e de uma conduta moral socialmente reconhecida.

Os novos padrões de produção e organização ocorridos nas últimas décadas do século $\mathrm{XX}$, as dinâmicas produtivas e as relações sociais de produção distintas das ocorridas em outras conjunturas do capitalismo têm gerado consequências fenomênicas bastante adversas, como o processo de diminuição do emprego estável e assalariado e assim, o crescente aumento do desemprego e do trabalho precário. Todavia, apesar de todas as metamorfoses pelas quais o mundo do trabalho tem passado, sustenta-se que este não deixou de constituir uma categoria importante e central para se compreender as ações humanas na sociedade contemporânea (Antunes, 2000; Castel, 1998).

A ideia de flexibilidade contida nos novos modelos produtivos pode ser compreendida, de acordo com Vasapollo (2006), de diversas maneiras: flexibilidade salarial, flexibilidade de horário, flexibilidade funcional, etc. Para Sennett (2001), a noção de flexibilização atinge os próprios trabalhadores ao exigir que estes sejam capazes de se adaptar às constantes mudanças nos processos produtivos. Castel (1998) sugere que a flexibilidade pressupõe a moldagem dos trabalhadores, o que significa não apenas uma adaptação mecânica às diferentes tarefas mas também, e principalmente, uma constante adaptação subjetiva.

Além disso, o slogan da flexibilidade e da desregulamentação, que domina o atual mundo do trabalho, representa a expulsão cada vez maior de mais pessoas do processo de trabalho, a intensificação do trabalho e até o prolongamento da jornada para muitos daqueles que nela estão inseridos (Mészáros, 2006).

Segundo Antunes (2000), na era do taylorismo/fordismo, ergueu-se um sistema de compromisso e de regulação que, limitado aos países capitalistas avançados, oferecia a ilusão de que o sistema de metabolismo social do capital pudesse ser efetiva e duradouramente controlado, regulado e fundado em um compromisso entre capital e trabalho mediado pelo Estado. Os trabalhadores possuíam um horizonte desenhado pela perspectiva de emprego para toda a vida dentro de uma empresa. Esse período se caracterizava, ainda, pela pequena variação do trabalho (pelo menos, em relação à flexibilização atual), que se baseava em uma concepção de tempo linear e previsível e que possuía como marca registrada a rotina. Alimentava, assim, a mentalidade de longo prazo (Bauman, 2001), que inclúa a ideia (ou efeito ideológico) de que os destinos das pessoas que compram o trabalho e daquelas que o vendem estão entrelaçados por muito tempo, ou seja, faziase necessária a construção de um modo de convivência suportável que corresponderia aos interesses de todos.

Com relação ao Brasil, onde nunca se assistiu à estabilidade acima apresentada, foi nos anos 90 que a reestruturação produtiva do capital se desenvolveu intensamente, por meio da implantação de vários receituários oriundos da acumulação flexível e do ideário japonês (Antunes, 2000). Foi, portanto, nesse período que se intensificou o processo de reestruturação produtiva do capital em nosso país, processo que vem se efetivando mediante formas diferenciadas, configurando uma realidade que comporta elementos tanto de continuidade como de descontinuidade 
em relação às fases anteriores. Em síntese, verifica-se uma mesclagem entre elementos do fordismo, que ainda encontram vigência acentuada, e elementos oriundos das novas formas de acumulação flexível e/ou influxos toyotistas. De todo modo, assiste-se, no Brasil, a enormes enxugamentos de força de trabalho, combinados com mutações sociotécnicas no processo produtivo e na organização do controle social do trabalho.

Todas essas mudanças, aliadas ao movimento de desestruturação do mercado de trabalho no País, revelam, de certa forma, a natureza e a dimensão da atual da crise do emprego (Pochmann, 2004). Essa realidade vem afetando diretamente a juventude, atingida em cheio pela restrição das oportunidades de emprego e pela reestruturação das empresas. Os jovens foram vítimas também do encolhimento das oportunidades nas bases da pirâmide ocupacional, que fizeram com que desaparecessem muitas formas de entrada no mercado de trabalho.

\section{Juventude e projeto de vida}

A juventude, assim como as outras fases da vida, é uma construção social, histórica e cultural, de modo que, em cada momento histórico, ela possui funções, representações e significações diferenciadas. Sendo considerada por Groppo (2000) como categoria social, ela pode ser entendida como uma concepção, representação ou criação simbólica fabricada pelos grupos sociais ou pelos próprios indivíduos tidos como jovens para simbolizar uma série de comportamentos e atitudes a ela atribuídos. A concepção de juventude que permanece vigente, ainda segundo o autor, é originada da cultura e da sociedade ocidental capitalista, burguesa e liberal do século XIX, marcada por caracteres definidores e legitimadores cientificistas.

No século XX, a afirmação da juventude como força de transformação fez com que essa fase da vida se expandisse, empurrando a infância para trás e a maturidade para a frente. Para Ariès (1981), passamos de um período sem adolescência para outro, em que esta se tornou a idade favorita: a juventude se tornou um território onde todos, independentemente da idade, querem viver indefinidamente.

As maneiras de experimentar e vivenciar a juventude variam de acordo com as diferenças de classe, etnia, gênero, etc. (Castro \& Corrêa, 2005; Fraga \& lunianelli, 2003). A juventude não é homogênea, ela é múltipla, sendo então mais apropriado, na concepção desses autores, falar em juventudes. Apesar das particularidades existentes, diversas questões são impostas à maioria dos jovens no mundo contemporâneo, fazendo com que eles tenham que vivenciá-las, mesmo que de maneiras diferentes, de acordo com os contextos cultural, social e econômico nos quais se encontram.

Conforme apontam Levi e Schmitt (1996), a juventude se caracteriza por estar situada entre a dependência infantil e a autonomia adulta; ela é um devir, um período de transição. Pensando no aspecto transitório dessa fase, a juventude pode ser considerada um momento de preparação para a vida adulta. No entanto, com as mudanças ocorridas no mundo, essa preparação se tornou muito mais difusa e difícil.

A noção de preparação para a vida adulta está intimamente ligada à forma com que a ideia de tempo foi instituída dentro da sociedade ocidental, e traduz os esforços dos homens para se situarem no interior do fluxo incessante dos acontecimentos (Elias, 1998). O conceito de tempo, de acordo com o autor, não apenas oferece, do ponto de vista social, a função de coordenação e de integração das atividades humanas mas também, do ponto de vista subjetivo, a ideia de certa consistência pessoal (ou identidade pessoal, conforme o autor) constituída por um encadeamento de acontecimentos sucessivos que se organizam a partir de uma sequência irreversível, fornecendo a experiência de continuidade.

Logo, na experiência humana, e somente nela, se encontram essas grandes linhas demarcatórias entre ontem, hoje e amanhã que, seguindo uma lógica sequencial, fornecem um sentido de continuum à diversidade de 
vivências pessoais que, unidas, formam uma história de vida.

É a partir dessa ideia de biografia e de história de vida que se constrói, conforme ressalta Velho (1999), o projeto de vida. Os projetos individuais são desenvolvidos, assim, em torno dessa noção de tempo com etapas se encadeando, que implica a elaboração de planos e condutas orientadas para atingir determinados fins, em uma tentativa de dar sentido ou coerência às experiências vividas. Ainda de acordo com Velho (1999), o projeto de vida é uma noção que está intimamente ligada à de indivíduo construída na sociedade ocidental, sustentado por duas concepções nela contidas. A primeira, o ponto de partida para se pensar em projeto, se refere à noção de que os indivíduos escolhem ou podem escolher. A segunda está ligada à ideia de que cada um é portador de um conjunto de potencialidades peculiar, que constitui sua marca própria, e de que sua história (biografia) é uma atuação mais ou menos bem-sucedida destas. Logo, o projeto carrega consigo a necessidade colocada na sociedade ocidental de que é preciso definir e descobrir o que o indivíduo quer e pretende, ou seja, de alguma forma, o indivíduo precisa se distinguir, diferenciar-se de sistemas mais amplos.

Dessa forma, os projetos, longe de serem naturais e inerentes ao sujeito, são elaborações e construções realizadas em função de experiências socioculturais, de vivências e de interações interpretadas, devendo ser, portanto, sempre relativizados.

O projeto como conjunto de ideias e formas de conduta está sempre ligado a outros projetos e condutas localizáveis no tempo e no espaço. O que a noção de projeto procura é dar conta da margem relativa de escolha que indivíduos e grupos têm em determinado momento histórico de uma sociedade.

Dubar (2005) fala de configurações identitárias resultantes da articulação de uma dupla dimensão: a biográfica e a relacional. A primeira dimensão se refere à construção no tempo, pelos indivíduos, de identidades sociais e profissionais a partir das categorias oferecidas pelas instituições sucessivas: família, escola, mercado de trabalho, empresa. Já a segunda dimensão concerne ao reconhecimento, em um momento dado e no interior de um espaço determinado, de legitimação das identidades associadas aos saberes, competências e imagens de si propostos e expressos pelos indivíduos nos sistemas de ação.

De uma maneira ou de outra, mesmo partindo de referenciais teóricos diferenciados, o conceito de projeto elaborado por Velho (1999), sem abordar a noção de identidade, acaba por relacionar as duas dimensões da construção identitária explicitadas por Dubar (2005) - biográfica/subjetiva e relacional/ objetiva - ao deixar claro que os projetos de vida são elaborações subjetivas que se dão dentro de contextos objetivos específicos e que, portanto, sua formulação só poderá acontecer na articulação feita pelos sujeitos dessas duas dimensões.

\section{A pesquisa empírica}

Munidas dos conceitos básicos anteriormente delineados, realizou-se pesquisa empírica qualitativa com o objetivo de captar, de forma mais refinada, o universo de significados, motivos, aspirações, crenças e valores de um grupo específico de jovens. O instrumento de coleta de dados utilizado foi a entrevista semiestruturada, realizada através de roteiro com tópicos-guia que funcionaram como orientadores para as conversas com os entrevistados.

Pelo caráter múltiplo e heterogêneo da juventude, foi realizado um recorte desse universo para a realização do trabalho de campo, optando-se pela seleção de jovens que possuíssem realidades socioeconômicas e culturais similares. Dessa maneira, foram entrevistados sete jovens (quatro do sexo feminino e três do masculino), estudantes de graduação em diferentes áreas de conhecimento (administração, desenho industrial, engenharia eletrônica, história, jornalismo e publicidade) e de diferentes instituições de ensino (Instituto 
Militar de Engenharia - IME, Pontifícia Universidade Católica do Rio de Janeiro PUC-Rio, Univercidade, Universidade Federal Fluminense - UFF, Universidade Federal do Rio de Janeiro - UFRJ, Universidade Federal do Estado do Rio de Janeiro - UNIRIO), entre 21 e 26 anos, que exerciam função de estagiários de ensino superior em uma empresa nacional privada localizada no Estado do Rio de Janeiro e que pertenciam às classes média e média alta.

Com relação ao polêmico conceito de classe média, consideramos os critérios mais utilizados em outros estudos, em especial o de Pochmann, Pereira e Barbosa (2006): rendimentos auferidos (renda familiar per capita entre $\mathrm{R} \$ 1.064$ e $\mathrm{R} \$ 4.591$, conforme estudo da Fundação Getúlio Vargas, 2008), a posição ocupacional obtida no interior do mercado de trabalho e escolaridade e padrão de vida e de consumo razoáveis, de forma a não apenas suprir as necessidades de sobrevivência como também a permitirse formas variadas de lazer e cultura. Considerando o fato de os sujeitos analisados no presente estudo apresentarem renda próxima ao limite superior do estudo da FGV e possuírem educação formal de nível superior, sentimo-nos autorizados, ainda, a considerálos como de classe média alta.

A opção por estagiários (nas áreas de assessoria de imprensa, direção de arte, marketing, pesquisa de documentação, planejamento, projetos de engenharia e recursos humanos) se deveu ao fato de esses jovens estarem iniciando a experimentação no mundo do trabalho, pois, apesar de já terem se inserido no mercado, encontram-se em fase de treinamento através de estágio. Localizam-se, dessa maneira, em uma fase de construção de trajetórias profissionais e de vida, o que faz com que suas vivências e experiências estejam diretamente ligadas ao tema do estudo.

Para a análise do material coletado, optou-se, preliminarmente, por classificar as respostas em temáticas significativas, conforme os pressupostos metodológicos da análise de conteúdo, que foi orientada, conforme ressalta González Rey (2002), para a produção de indicadores sobre o material analisado. Dessa maneira, foram criados tópicos abrangentes de forma a organizar e a agrupar os conteúdos que giravam em torno de temas similares. Cada tópico constituiu, assim, tema amplo, a partir do qual foram desenvolvidos subtemas.

Após a definição dos temas e subtemas, com o objetivo de compreender os discursos dos jovens em torno destes e investigar as condições de sua produção - contexto e processo - foram utilizadas, como método para interpretação, as recomendações teórico-metodológicas da análise do discurso, conforme propostas por Orlandi (2007) e Rocha e Deusdará (2005). Entendeu-se, pois, que, para além da perspectiva do conteúdo, um modelo duro, rígido, e até de corte positivista em muitas de suas versões, dever-se-ia considerar na análise a espessura que compõe a relação entre o texto e o seu entorno, visando predominantemente ao debate do modo como a enunciação é capaz de inter-relacionar "uma organização textual e um lugar social determinados" (Rocha \& Deusdará, 2005, p. 315), de realçar a articulação linguagem e sociedade, entremeadas pelo contexto ideológico. Além disso, considerou-se, para além do rigor metodológico tão claramente manifestado pela perspectiva da análise de conteúdo, o detalhamento das implicações dos pesquisadores em relação ao objeto.

A análise do material obtido permitiu a construção de uma gama de tópicos ligados aos interesses do estudo, dentre os quais os mais representativos em termos de enriquecimento para a temática pesquisada foram agrupados nas categorias desenvolvidas a seguir.

\section{Estágio: um aprendizado do perfil}

As percepções, vivências e experiências relatadas pelos entrevistados sobre os estágios que realizam ou realizaram remeteram, de maneira direta ou indireta, a um importante aprendizado, conforme expressão dos próprios depoentes, à construção pessoal 
ou à adequação a um determinado perfil valorizado e reconhecido no atual mercado de trabalho.

Os jovens argumentaram que, para começar a ingressar na vida profissional, é necessário ter talento, apresentar esse perfil que se traduz não só em aprender a realizar as tarefas relacionadas às suas áreas de atuação: o saber-fazer mas, principalmente, em adquirir maneiras de se portar e de se relacionar: o saber-ser. Para eles, o saber-ser refere-se à possibilidade de mostrar que se tem uma série de características de personalidade, nomeadas, por vezes, de competências, que tornariam o jovem profissional capacitado a atingir altos desempenhos, como assinalado por um estudante de engenharia, de 24 anos: "enquanto os processos estavam ocorrendo, eu vi também outra coisa que eu não dava tanto enfoque, era a desenvoltura pra falar, essa parte mais de relacionamento, saber se expressar de uma forma clara, eu acho que isso foi uma coisa que me deu um choque. Caramba! Isso eu tenho que prestar bastante atenção, tenho que me esforçar pra desenvolver esse lado".

Afirmações como essa vão ao encontro das análises de Lipovetsky (2007), quando destaca que a nova configuração do trabalho (baseada nas premissas do sistema toyotista) carrega, como forma de sustentação para o alcance de seus objetivos, discursos de gestão fortemente centrados nos potenciais dos indivíduos, trazendo à tona a valorização das competências, que se ligam a comportamentos ou características pessoais: flexibilidade para adaptação às mudanças, autodesenvolvimento, comunicação, empreendedorismo, espírito de equipe, inovação/criatividade, liderança e impacto são algumas das competências valorizadas pelas empresas na atualidade, em uma verdadeira transposição dos ideais e das práticas de competitividade das próprias empresas para os que nelas trabalham. Nos atuais discursos de gestão, há, portanto, um chamado a cada profissional para o aperfeiçoamento e o empenho contínuos. É um discurso que faz um apelo cada vez maior para que os trabalhadores mobilizem e engajem suas subjetividades no alcance dos resultados esperados pela empresa.

É nesse contexto que se dá a emergência do saber-ser como importante conhecimento a ser desenvolvido ao longo da vida profissional, conforme assinalado fartamente pelos entrevistados, tanto para a participação nos processos seletivos quanto para o aprendizado buscado dentro dos estágios. A fala da estudante de administração, de 26 anos, bem exemplifica o que se está a afirmar: "aprendo aqui de tudo, não só da área, mas como entrar numa reunião, como falar com uma pessoa no telefone, tudo, acho que tudo que eu estou aprendendo aqui vai ser importante... até pra eu escolher realmente o que eu quero ser".

No entanto, a ênfase dada pelos jovens aos modos de se portar parece remeter a um saber para além do saber-ser, um saber mais voltado para a constituição de uma determinada imagem: um saber-parecer.

O saber-parecer está diretamente ligado à noção de perfil para um conjunto de competências, que, mesmo que não se tenha, precisa ser declarado. A própria palavra perfil carrega a noção do saber-parecer. Podemos encontrar os seguintes significados para a palavra perfil, segundo o Dicionário Aurélio (Buarque de Holanda, 2004): contorno de rosto da pessoa vista de lado; representação de um objeto que é visto só de um lado; contorno, silhueta e descrição de alguém em traços rápidos. Nesse sentido, o perfil remete a uma ideia mais superficial na captura do outro, lembrando a primazia do olhar e da imagem (Sevcenko, 2001).

Ter experiência em um lugar grande (como se reportavam à empresa do estágio) apresentavase no discurso dos jovens como mais um importante fator para a construção de uma determinada imagem valorizada pelo mercado de trabalho. O lugar grande não precisa ocupar geograficamente um espaço significativo; lugar grande adquire um novo significado: é o lugar que projeta, que causa impacto pelo nome. Transforma-se, dessa maneira, em um signo 
para ser rapidamente capturado pelo olhar do outro, captura que, nesse caso, é feita por meio do currículo.

Assim, a constituição da imagem através de signos representa, como lembra Harvey (1994), diante da enorme competitividade, um poderoso elemento na autoapresentação desses jovens, passando a ser parte integrante da sua busca individual.

O sujeito dos tempos atuais definido por Lipovetsky (2004) como: flexível, organizado, responsável, que vive em uma verdadeira corrida contra o tempo e que está sempre atarefado também compareceu nas falas dos entrevistados ao se referirem às rotinas de estágio. Por outro lado, o estresse provocado pelo cotidiano inflado de atividades e o agir sob o ritmo da urgência não pareceu afetar os depoentes, pelo contrário, estar sempre atarefado representaria um status, como na fala da estudante de jornalismo, de 23 anos: "acho que todo mundo, para se sentir importante, tem que estar atarefado". Estar atarefado significa, enfim, uma maneira de pertencimento e da adequação a uma realidade que consideram natural, positiva e inerente ao bom trabalho.

\section{Conexões no mercado de trabalho: os contatos}

Outra categoria que permeou quase todos os tópicos abordados pelos entrevistados foram os contatos, que emergem como facilitadores para a inserção e a permanência no mercado de trabalho.

Ter e fazer contatos parece fundamental para esses jovens, de maneira que o aprendizado prático da profissão, possibilitado pelo estágio, ou mesmo o conhecimento oferecido pela universidade em que estudam, parecem figurar em segundo plano. Na realidade, estágio e universidade são dois ambientes percebidos como essenciais, principalmente pelo fato de oferecerem a possibilidade de estabelecer contatos.
Contatos se têm, se adquirem, se fazem. Demonstram a emergência de maneiras diferenciadas de relacionar-se dentro do universo do trabalho, uma forma de relacionamento que se apresenta como rede, um estabelecimento de conexões pouco ou nada pessoais, nas quais as ligações são mantidas na medida em que são úteis para o sujeito.

Os contatos se agrupam formando as redes de relacionamento que um sujeito possui, e estas vão sendo estabelecidas aos poucos, através dos estágios, da universidade e de outros locais variados. Estar em uma grande rede de relacionamentos não só representa a possibilidade de rápida reinserção no mercado mas também aparece como certo símbolo de status. Uma estudante de publicidade, de 23 anos, refere-se enfaticamente ao tema: "quando você está dentro do mercado de trabalho, é muito mais fácil você desenvolver um network (para que) possa voltar a trabalhar mais rápido".

O network remete ao linguajar da tecnologia e dos computadores: conexões mantidas entre pessoas que trabalham juntas como um sistema. O network se apresenta como a ação de estabelecer e manter contatos, referindo-se, portanto, a uma forma específica de relacionarse socialmente, considerada fundamental para os jovens entrevistados. Estabelecer contatos é, no entanto, como sustenta Bauman (2001, 2004), uma forma de relacionamento realizada a partir de frágeis laços. Os relacionamentos estabelecidos por esses jovens parecem ser guiados pelo ideal de conectividade, sendo transformados em verdadeiras redes, regidas pela lógica da utilidade, e constituem relações úteis estabelecidas com um intuito específico: pertencer ao mercado de trabalho. E, assim, o ideal da conectividade mantém como base de sustentação, nesse caso, a lógica do que é útil para cada um individualmente; remete à afirmação de Castel (1998) de que o contexto no qual se vive atualmente acaba por construir na sociedade um individualismo negativo: cada um deve pensar primordialmente em si mesmo, na tentativa de não ficar à deriva. 


\section{A entrada na vida adulta e o futuro: o mosaico de possibilidades}

Segundo Heller (1989), o processo de amadurecimento significaria que uma pessoa adquiriu uma série de habilidades imprescindíveis para a vida cotidiana na sociedade em que vive, ou seja, os adultos seriam aqueles capazes de viver por si mesmos a sua cotidianidade, seriam aqueles que teriam aprendido não apenas os comportamentos necessários para viver em sociedade como também seriam capazes de deixar o grupo familiar, adquirindo, dessa maneira, autonomia.

Se considerássemos essa perspectiva da autora, nenhum dos entrevistados poderia ser considerado adulto, pois todos ainda mantinham relações de dependência financeira/afetiva com a família. No entanto, acreditavam-se pertencentes ao mundo adulto a partir de uma nova definição, atrelada a fatores subjetivos e internos, a construção de uma cabeça, como argumentado por uma estudante de publicidade, de 23 anos: "eu acho (que sou adulta) porque tenho minha consciência, cabeça formada, eu tenho opiniões, eu consigo debater com as pessoas sobre as minhas opiniões, e não abaixo a cabeça".

Parece que, dentro do cenário contemporâneo, que muitas vezes dificulta a possibilidade de os jovens adquirirem autonomia, principalmente no sentido financeiro, as passagens pelas etapas da vida têm se tornado cada vez menos rígidas, transformando-se em verdadeiras posições de passagem. Essas posições poderiam se imbricar, desaparecer e até mesmo se repetir. Essa indefinição acaba por aparecer no discurso dos entrevistados como a criação de um novo significado para a etapa adulta: a posição da cabeça.

Quanto ao futuro e à noção de longo prazo, os discursos dos entrevistados parecem corroborar a afirmação de Bauman (2001), quando analisa que, dentro do cenário moderno, o futuro aparece como uma concha vazia de significados. A noção de longo prazo soa de maneira estranha, como algo difícil até mesmo de ser imaginado diante das inúmeras e rápidas mudanças que percebem acontecer em seu redor. O estudante de administração, de 23 anos, expressou-se claramente a respeito: "a longo prazo, eu não tenho (idéia), eu tenho a curto prazo"; "daqui a trinta anos..., não existe".

Inquiridos sobre os planos para o futuro, respondem com grandes sonhos, em que o principal, no campo do trabalho, é a realização profissional. Foi na abordagem desse aspecto que surgiu o medo, no discurso dos jovens, relacionado à possibilidade de não conseguirem realizar seus sonhos, de não serem reconhecidos como esperam, de ficarem estagnados ou de não conseguirem fazer nada. Na realidade, temem o oposto da lógica do movimento na qual aparecem inseridos na atualidade.

No entanto, mesmo a esses temores não foi concedida tanta importância, pois os medos quanto ao futuro acabavam por ficar embaçados diante do otimismo do presente, sustentado pela crença em si mesmos, em seus potenciais e talentos. Foi recorrente, no discurso dos jovens, a ideia de que, se quiserem muito e se correrem atrás do que querem, serão capazes de conseguir o que desejam, apesar de todas as dificuldades que o mercado de trabalho apresenta.

É no curto prazo que os entrevistados apresentam algum conforto de atuação e até mesmo de capacidade de planejamento. O curto prazo é problematizado e ganha lugar de destaque para esses sujeitos. O campo de ação desses jovens se sustenta nessa noção, e mesmo seus planos (abordados acima), na verdade, se referem a ações mais imediatas para questões que estão prestes a surgir em suas vidas: acabar a faculdade, conseguir uma colocação no atual estágio. Assim, atuam dentro de um presente estendido, conforme proposto por Leccardi (2005), ou, como preferimos chamar, de um futuro encurtado. 
O futuro é aludido no campo dos sonhos e desejos, das múltiplas oportunidades que os entrevistados enxergam para si, mas que não aparece integrado a estratégias de ação específicas para o seu alcance. Na realidade, o presente estendido é o campo no qual eles realmente atuam, buscando conseguir pequenos objetivos imediatos.

O projeto de vida tal como pontuado por Velho (1999) representaria a possibilidade de projetar um futuro desejado e elaborar maneiras de atingi-lo, carregando a noção da trajetória de vida como uma possibilidade de atualização dos potenciais individuais.

Para os jovens entrevistados, os projetos se relacionam a ações voltadas para o curto ou o curtíssimo prazo, e o futuro emerge não como uma trajetória, mas como um mosaico de possibilidades, "as muitas portas que existem atualmente", como definiu uma estudante de jornalismo, de 23 anos. São, portanto, múltiplos projetos caracterizados pela mutabilidade (podem ser alterados de acordo com as oportunidades que surgirem) e que possuem uma estratégia de ação principal: ninguém pode ficar parado. $\mathrm{O}$ nomadismo é fortemente vinculado a esses projetos de vida, à possibilidade de viajar, de mudar de emprego, de alterar atividades, etc. A ideia de manter as portas abertas também se faz presente como meio para não perder as oportunidades que aparecerem. São projetos que parecem adaptar-se ao contexto atual...

\section{Considerações finais}

Os resultados obtidos nas entrevistas permitiram observar a importância que $\mathrm{o}$ trabalho possui na construção subjetiva dos jovens entrevistados. Ele parece constituir um importante valor e ter como fundamental instância para a sua formação como sujeitos no sentido de ser um meio de realização dos sonhos e desejos pessoais.

Apesar de o trabalho poder constituir meio de transformação do contexto em que se vive, para esses jovens, ele se coloca apenas como possibilidade de realização de desejos de caráter meramente individual. Mesmo tendo falado sobre o difícil cenário em que se encontram, principalmente em termos da violência com a qual convivem, não se consideram possíveis agentes de mudança. A realidade aparece como um dado, um fato no qual não cabe a eles interferir, restando apenas, portanto, a ela se adaptarem. Nesse sentido, os projetos de vida construídos pelos jovens apontam para a mesma direção: são projetos também de natureza individual. Com a noção de projeto de vida, abordada neste trabalho através das concepções de Velho (1999), ou seja, um conceito elaborado a partir das possibilidades oferecidas aos sujeitos em contextos culturais, sociais e econômicos específicos, a forma de configuração do contemporâneo parece empurrar os jovens cada vez mais em direção à construção de projetos aos quais os interesses coletivos não são integrados.

Dessa maneira, os projetos de vida apresentados pelos jovens pesquisados carregam em si muitas características inerentes ao contexto contemporâneo e às próprias maneiras como o trabalho se configura, parecendo quase um retrato destes. São permeados pelas ideias de flexibilidade, mudança, aceleração, movimento constante e abertura ao novo, entre outras características destacadas nas análises realizadas por autores como Bauman (2001) e Lipovetsky (2004).

As trajetórias e narrativas de vida desses jovens parecem constituir um caminho de múltiplas e diferenciadas possibilidades, permitido pelo seu contexto socioconômico, que vai sendo construído como um mosaico ao qual cada experiência, como uma peça, é pouco a pouco inserida.

O projeto de vida não é único, mas vai sendo formado por múltiplos e variados projetos caracterizados pela mutabilidade; sendo assim, vão sendo alterados de acordo com as possibilidades e oportunidades a eles apresentadas. Seus projetos são guiados, no entanto, por uma certeza: ninguém pode ficar parado. É o movimento, em sua ampla gama de significados e em todos os sentidos e direções, 
que conduz à estratégia para conseguirem realizar seus sonhos, vigorando a lógica do cada um por si.

A crença nas próprias capacidades e a dedicação que empregam em seu desenvolvimento profissional, por um lado, e as dificuldades do mercado de trabalho - a alta competitividade, a exigência de ampla qualificação e a escassez de emprego -, por outro, leva esses jovens a flutuar entre esperanças e medos. Apesar de acreditarem que o futuro e o sucesso profissional dependem do esforço e do talento de cada um individualmente-estariam, assim, em suas mãos -, seus projetos denotam o quanto suas escolhas estão sujeitas a fatores externos, à forma como as possibilidades serão a eles apresentadas.

A ideia de que o futuro depende de cada um individualmente não é questionada por esses jovens, mas está arraigada em seus discursos, constituindo quase uma verdade universal inerente ao mundo em que vivem. É, portanto, a própria ideologia neoliberal e suas lógicas baseadas na competitividade e na colocação do indivíduo como o mais importante elemento dentro da sociedade que parecem sustentar suas crenças, sentimentos, ações e integrar-se na constituição de seus projetos de vida.

As características inerentes ao atual cenário do trabalho parecem marcar fortemente a constituição subjetiva desses jovens, trazendo à tona formas de se relacionar, de se portar e de falar ligadas às práticas e aos discursos organizacionais em vigor.

Assim, as trajetórias de vida dos jovens pesquisados vêm sendo construídas dentro de um cenário que apresenta diversos desafios, de maneira cada vez mais nômade e individualizada. Parece, portanto, que esses jovens se encontram mais na tentativa de se adaptar ao contexto dado do que de pensar em maneiras de nele atuar para alterá-lo. Já que essa possibilidade é colocada diante deles, se a realidade na qual vivem não lhes agrada, é mais fácil trocar de realidade: mover-se, viajar, mudar; no entanto, esses jovens não são irresponsáveis e pouco comprometidos, pelo contrário, são muito dedicados e responsáveis, mas o seu compromisso é consigo mesmos e com aquilo que acreditam possibilitar a realização dos seus sonhos pessoais.

É importante destacar que, pelo recorte utilizado para a realização do estudo, os resultados apresentados se referem a uma determinada realidade, por se situarem em contextos social, econômico e culturalmente específicos (classe média alta, carioca, universitários, estagiando em uma grande e famosa empresa), não cabendo, portanto, generalizações para outros grupos distintos. De qualquer forma, instigam ao estudo dos processos de produção da subjetividade de outras juventudes de nosso país que possam contribuir para se considerar caminhos alternativos e, principalmente, coletivos, para os jovens dentro da realidade brasileira.

\section{Ana Augusta Ravasco Moreira Maia}

Doutoranda do Programa de Pós-Graduação em Psicologia Social da Universidade do Estado do Rio de Janeiro, Rio de Janeiro, RJ - Brasil.

E-mail: ana.ravasco@gmail.com

\section{Deise Mancebo*}

Doutora em História da Educação pela Pontifícia Universidade Católica de São Paulo, Pós-Doutorado em Psicologia Social pela Universidade de São Paulo, São Paulo, SP - Brasil. Professora titular da Universidade do Estado do Rio de Janeiro, Rio de Janeiro, RJ - Brasil.

\section{*Endereço completo para correspondência:}

Rua Barão de Cotegipe, 416, casa 7, Vila Isabel - Rio de Janeiro, RJ - Brasil - CEP 20560-080.

E-mail: deise.mancebo@gmail.com 


\section{Referências}

Antunes, R. (2000). Os sentidos do trabalho: ensaios sobre a afirmação e a negação do trabalho (2a ed.). São Paulo: Boitempo.

Ariès, P. (1981). História social da criança e da família (2a ed.). Rio de Janeiro: Jorge Zahar.

Bauman, Z. (1999). Globalização: as consequências humanas. Rio de Janeiro: Jorge Zahar.

Bauman, Z. (2001). Modernidade líquida. Rio de Janeiro: Jorge Zahar.

Bauman, Z. (2004). Amor líquido: sobre a fragilidade dos laços humanos. Rio de Janeiro: Jorge Zahar.

Buarque de Holanda, A. (2004). Novo dicionário Aurélio da língua portuguesa (5a ed.). São Paulo: Positivo.

Castel, R. (1998). As metamorfoses da questão social: uma crônica do salário (2a ed.). Petrópolis, RJ: Vozes.

Castro, L. R., \& Correa, J. (2005). Juventudes, transformações do contemporâneo e participação social. In L. R. Castro \& J. Correa (Eds.), Juventude contemporânea: perspectivas nacionais e internacionais (pp. 9-16). Rio de Janeiro: Nau.

Dubar, C. (2005). A socialização: construção de identidades sociais e profissionais. São Paulo: Martins Fontes.

Elias, N. (1998). Sobre o tempo. Rio de Janeiro: Jorge Zahar.

Fraga, P. C. P., \& luianelli, J. A. S. (2003). Introdução: juventude para além dos mitos. In P. C. P. Fraga \& J. A. S. luianelli (Eds.), Jovens em tempo real (pp. 9-16). Rio de Janeiro: DP\&A.

Fundação Getúlio Vargas. (2008). Panorama de evolução da renda e classes econômicas. Rio de Janeiro: FGV. Recuperado em 24 de agosto de 2009, de http://www3.fgv.br/ibrecps/credi3/ TEXTO_panorama_evolucao.htm

Gonçalves, M. G. M. (2002). Fundamentos metodológicos da psicologia sócio-histórica. In A. M. B. Bock (Ed.), Psicologia sócio-histórica: uma perspectiva crítica em Psicologia (2a ed.; pp. 113-128). São Paulo: Cortez.

González Rey, F. L. (2002). Pesquisa qualitativa em psicologia: caminhos e desafios. São Paulo: Pioneira Thomson Learning.

Groppo, L. A. (2000). Juventude: ensaios sobre sociologia e história das juventudes modernas. Rio de Janeiro: DIFEL.

Harvey, D. (1994). Condição pós-moderna (4a ed.). São Paulo: Loyola.

Heller, A. (1989). O cotidiano e a história (3a ed.). São Paulo: Paz e Terra.
Leccardi, C. (2005). Para um novo significado do futuro: mudança social, jovens e tempo. Tempo Social, 17(2), 35-57.

Levi, G., \& Schmitt, J. C. (1996). História dos jovens 1: da antiguidade à era moderna. São Paulo: Companhia das Letras.

Lipovetsky, G. (2004). Os tempos hipermodernos. São Paulo: Barcarolla.

Lipovetsky, G. (2007). A felicidade paradoxal: ensaio sobre a sociedade de hiperconsumo. São Paulo: Companhia das Letras.

Mancebo, D. (2004). Indivíduo e psicologia: gênese e desenvolvimento atuais. In D. Mancebo \& A. M. Jacó-Vilela (Eds.) Psicologia social: abordagens sócio-históricas e desafios contemporâneos (2a ed., pp. 35-48). Rio de Janeiro: EdUERJ.

Mészáros, I. (2006). Desemprego e precarização: um grande desafio para a esquerda. In R. Antunes (Ed.), Riqueza e miséria do trabalho no Brasil (pp. 27-44). São Paulo: Boitempo.

Orlandi, E. P. (2007). Análise de discurso: princípios e procedimentos (7a ed.). São Paulo: Pontes.

Pochmann, M. (2004). Juventude em busca de novos caminhos no Brasil. In R. Novaes \& P. Vannuchi (Eds.), Juventude e sociedade: trabalho, educação e participação (pp. 217-241). São Paulo: Fudação Perseu Abramo.

Pochmann, M., Pereira, M., \& Barbosa, A. (2006). Atlas da nova estratificação social no Brasil: classe média, desenvolvimento e crise. São Paulo: Cortez.

Rocha, D., \& Deusdará, B. (2005). Análise de conteúdo e análise do discurso: aproximações e afastamentos na (re)construção de uma trajetória. Alea, 7(2), 305-322.

Sennett, R. (2001). A corrosão do caráter: consequências pessoais do trabalho no novo capitalismo (5a ed.). Rio de Janeiro: Record.

Sevcenko, N. (2001). A corrida para o século XXI: no loop da montanha russa. São Paulo: Companhia das Letras.

Vasapollo, L. (2006). O trabalho atípico e a precariedade elemento estratégico determinante do capital no paradigma pós-fordista. In R. Antunes (Ed.), Riqueza e miséria do trabalho no Brasil (pp. 45-58). São Paulo: Boitempo.

Velho, G. (1999). Individualismo e cultura: notas para uma antropologia da sociedade contemporânea (5a ed.). Rio de Janeiro: Jorge Zahar. 